\title{
ВІДБІР ІНФОРМАТИВНИХ ПОКАЗНИКІВ ВАРІАБЕЛЬНОСТІ РИТМУ СЕРЦЯ - МАРКЕРІВ РЕАКЦІЇ НА ЕМОЦІЙНІ СТИМУЛИ
}

\author{
О. А. Кривова, І. А. Чайковський ${ }^{1}$, В. В. Кальниш ${ }^{2}$, Л. М. Козак \\ Міжнародний науково-навчальний центр інформаційних технологій \\ та систем НАН та МОН України \\ 1 Інституткібернетики імені В. М. Глушкова НАН України \\ ${ }^{2}$ ДУ «Інститут медицини праці НАМН України»
}

\begin{abstract}
На основі методів багатовимірного статистичного аналізу розроблено методику виділення інформативних показників варіабельності ритму серця (ВРС), що мають діагностичну цінність для об'єктивної оцінки реакції операторів на емоційно забарвлені відеокліпи. Методика складається з двох етапів: 1) багатомірного дисперсійного аналізу; 2) покрокового дискримінатного аналізу з різними стратегіями відбору ознак. Загальна середня точність класифрікації чотирьох станів операторів за 10 інформативними показниками (два з яких - за результатами самозвіту, а інші показники варіабельності ритму) досягала 95,7\%.
\end{abstract}

Ключові слова: варіабельність серцевого ритму, емоційно забарвлені відеокліпи, дисперсійний аналіз, лінійний дискримінантний аналіз.

\section{ОТБОР ИНФОРМАТИВНЫХ ПОКАЗАТЕЛЕЙ ВАРИАБЕЛЬНОСТИ РИТМА СЕРДЦА - МАРКЕРОВ РЕАКЦИИ НА ЭМОЦИОНАЛЬНЫЕ СТИМУЛЫ}

\author{
О. А. Кривова, И. А. Чайковский ${ }^{1}$, В. В Кальныш ${ }^{2}$, л.М. Козак \\ Международный научно-учебный центр информационных технологий \\ и систем НАН и МОН Украины \\ 1 Институт кибернетики имени В. М. Глушкова НАН Украины

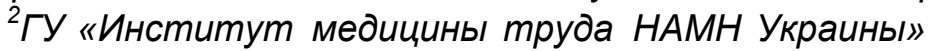

\begin{abstract}
На основе методов многомерного статистического анализа разработана двухэтапная методика выделения информативных показателей вариабельности ритма сердца (ВРC), имеющих диагностическую ценность для объективной оценки реакции операторов на эмоционально окрашенные видеоклипы. Методика состоит из двух этапов: 1) многомерного дисперсионного анализа; 2) пошагового дискриминантного анализа с различными стратегиями отбора признаков. Общая средняя точность классификации четырех состояний операторов по 10 информативным показателям (два из которых - по результатам самоотчета, а другие показатели - вариабельности ритма) достигала $95,7 \%$.
\end{abstract}

Ключевые слова: вариабельность ритма сердца, эмоционально окрашенные видеоклипы, дисперсионный анализ, пошаговый линейный дискриминантный анализ.

\section{SELECTION INFORMATIVE HEART RATE VARIABILITY MEASURES - MARKERS OF REACTION TO EMOTIONAL STIMULI}

\author{
O. A. Krivova, I. A. Chaikovsky ${ }^{1}$, V. V. Kalnysh ${ }^{2}$, L. M. Kozak \\ IRTC ITS of NAS of Ukraine \\ Glushkov \\ Institute of Cybernetics \\ ${ }^{2} S I$ «Institute for occupational health» NAMS of Ukraine
}

On the basis of multivariate statistical analysis developed method for the separation of informative indicators of heart rate variability (HRV), which have diagnostic value for the objective assessment of operator's emotional reaction from watching emotive videos. The technique consists of two stages: 1) multivariate analysis of variance; 2) stepwise discriminate analysis

(C) О. А. Кривова, І. А. Чайковський, В. В.Кальниш, Л. М. Козак 
with different strategies of feature selection. The total average classification accuracy 4 states of operators by 10 informative indices (two of which are indicators of the results of self -report and other indicators HRV) reached $95.7 \%$.

Key words: heart rate variability, emotional reaction, emotive stimuli, feature selection, stepwise discriminate analysis.

Вступ. Останніми роками активно проводиться пошук об'єктивних показників для діагностики емоційного стану людини. В психофізіології для діагностики емоційних реакцій разом із методом самооцінки традиційно застосовують аналіз змін показників активності вегетативної та центральної нервової системи під впливом тестових стимулів [1]. 3 метою автоматизованого розпізнавання емоцій виділяють характерні ознаки біомедичних сигналів (ЕКГ, ЕЕГ, ЕМГ, електричний опір шкіри тощо), що можуть бути індикаторами різних емоційних станів [2 -10]. Показники варіабельності ритму серця (ВРС) також розглядаються як діагностичні маркери емоційних реакцій і станів [2, 7 -9].

Накопичені експериментальні дані про об'єктивні показники відгуку на тестові емоційно забарвлені стимули мають суперечний характер, тому питання щодо базового набору індикаторів емоційної реакції залишається відкритим $[6,8]$. Окрім того, під час обробки та аналізу багатовимірних експериментальних даних виникає проблема вибору оптимального набору інформативних ознак, що адекватно описують емоційний стан і реакцію на тестовий стимул. Вирішення цієї проблеми сприятиме ефективному розпізнаванню емоцій за об'єктивними психофізіологічними показниками.

Мета дослідження: вдосконалити методику виявлення інформативних ознак для розпізнавання реакції на емоційно забарвлені стимули.

Завдання: виявити оптимальний набір показників ВРС для ефективної класифікації реакції оператора на емоційні стимули за допомогою методів дисперсійного та дискримінантного аналізу в поєднанні зі стратегіями відбору ознак.

Матеріали та методи досідження. Протокол експериментального дослідження впливу перегляду тестових відеокліпів, емоційний стан операторів та попередні результати подано в роботах $[11,12]$. Було проаналізовано 48 показників ВРС (в часовій, частотній області), отримані геометричними, нелінійними методами аналізу [13 - 17], а також два показники самооцінки емоційного стану операторів.

Результати та їх обговорення. Дослідження $\epsilon$ продовженням роботи [12], де розраховано статистичну оцінку впливу емоційних стимулів на деякі показники ВРС на груповому рівні, проте для ідентифікації емоційних реакцій на індивідуальному рівні отримані оцінки були замалими.

Для підвищення ефективності розпізнавання емоційних реакцій показників розроблено методику визначення оптимального набору інформативних ознак із застосуванням: на першому етапі багатовимірного дисперсійного аналізу, а потім - лінійного дискримінантного аналізу у поєднанні з різними стратегіями відбору ознак. Всі розрахунки виконувались із використанням системи STATISTICA 10.

Перший етап. Як відомо, інформативність ознак пов'язана зі структурною відмінністю даних, що характеризують досліджуваний процес. Інформативною ознакою вважатимемо ознаку, що має близькі значення на об'єктах одного класу і суттєво відмінні значення в іншому класі. Для відбору інформативних ознак застосовували статистичні критерії, а для виявлення оптимальної кількості таких ознак застосовували порівняння результатів розпізнавання (класифікації) за повним набором ознак і без урахування деяких ознак [18].

Для статистичної оцінки впливу фактора на комплекс корельованих змінних, як у нашому випадку, коректно застосовувати багатовимірний дисперсійний аналіз (MANOVA), а не перевіряти вплив стимулу на кожну змінну одновимірною процедурою ANOVA.

Фактором впливу на емоційний стан операторів були тестові стимули різної модальності (відеокліпи): позитивно, негативно та нейтрально забарвлені. Позначимо категоріальний фактор, що відповідає різним функціональним станам операторів: $N=\langle 0 »-$ в стані спокою; $N=«+»-$ під впливом позитивного стимулу; $N=\ll-»-$ негативного; $N=$ "_" - нейтрального стимулу.

Всі первинні змінні (50 ознак) перевірялися на виконання необхідних умов дисперсійного і дискримінантного аналізу: багатовимірний нормальний розподіл, схожість дисперсій і коваріаційних матриць груп, відсутність мультиколінеарності.

Для оцінки впливу стимулів на індивідуальному рівні було вибрано інший спосіб нормування даних - заміна вихідних значень стандартизованими відхиленнями від середнього кожного оператора. Це призвело до виділення значно більшої кількості інформативних ознак (33) порівняно з раніше отриманим набором $[11,12]$. Зазначимо, що раніше виділені 
показники ВРС також увійшли до цього переліку. Статистична оцінка впливу фактора на 33 змінні перевищує раніше отриману оцінку і дорівнює $\eta 2=0,77$, тобто дисперсія, зумовлена переглядом емоційних стимулів, становить 77 \% від загальної. Це враховує збільшення точності класифікації, проте великий набір інформативних ознак може виявитися надлишковим для ефективного розпізнавання, оскільки містить слабко корельовані ознаки. Необхідно зазначити, що з переліку значущих ознак тільки для однієї змінної $(L F)$ не виконується умова однорідності дисперсій груп (за критерієм Левене).

Другий етап. Дискримінантний аналіз є одним із класичних способів відбору ознак, за якими можна класифікувати спостереження, і поряд з іншими методами застосовується для розпізнавання емоцій за фізіологічними сигналами [2-4]. В нашому випадку завдання формулюється таким чином. С об'єкти 3 певними ознаками (показники самооцінки емоційного стану та показники ВРС операторів). Знаючи угруповання об'єктів (стан операторів на різних етапах дослідження), необхідно знайти лінійні комбінації таких ознак (дискримінантні функціі), за якими можна 3 високою ймовірністю сказати, до якого угрупування об'єкт належить.

На першому етапі аналізу (MANOVA) кількість первинних ознак знижено до тридцяти трьох, за якими істотно відрізняється середньогрупові відхилення показників в стані спокою та під впливом тестових стимулів. Подальше завдання - визначити, за яким набором індивідуальних ознак з високою ймовірністю можна віднести кожен об'єкт до того або іншого стану.
3 метою виділення оптимальної кількості змінних для ефективної класифікації спостережень проводилося тестування цих 33 ознак.

Для цього застосовували покроковий метод побудови дискримінантної моделі з різними стратегіями відбору змінних:

1) покроковий вперед із включенням (forward stepwise);

2) покроковий назад із виключенням (backward stepwise);

3) пряме включення (forward entry);

4) зворотне видалення (backward removal);

5) найкраща підмножина (best subset).

Покрокові методи базуються на послідовному приєднанні або виключенні ознак згідно з певним критерієм відбору. Зазвичай використовується критерій Фішера.

Стратегія 1. При покроковому відборі вперед початковий набір ознак нульовий, на кожному кроці перевіряється кожна змінна за умовою відбору і приєднується та, яка вносить найбільший вклад у дискримінацію. Причому включену на якомусь кроці змінну на якомусь наступному кроці може бути виключено 3 моделі. Умовою відбору був певний рівень статистичної значущості F -тесту: включення при $\mathrm{p} \leq 0,05$, виключення при $\mathrm{p} \geq=0,06$. На першому кроці в модель було включено змінну Average x із найбільшою дискримінантною здатністю. У підсумку в модель 1 відібрано 11 змінних (Average х, CAH, ND, SampEn, LF, Градусник, SI, F3n, SY, PNN50, RMSSD). Середня точність класифікації чотирьох станів (частка правильно визначених спостережень) за дискримінантною моделлю 1 становила 95,7 \%.

Таблиия 1

Результати багатовимірного тесту значущості моделі 1

\begin{tabular}{|l|c|c|c|}
\hline \multirow{2}{*}{ Дискримінантні змінні } & \multicolumn{3}{|c|}{ Критерії } \\
\cline { 2 - 4 } & Wilks $\lambda$ & $\mathrm{F}(3,102)$ & $\mathrm{p}$ \\
\hline СAH & 0,631890 & 19,8068 & 0,000000 \\
\hline Градусник & 0,824962 & 7,2140 & 0,000194 \\
\hline Average $\mathrm{x}$ & 0,574660 & 25,1655 & 0,000000 \\
\hline RMSSD & 0,926118 & 2,7124 & 0,048846 \\
\hline PNN50 & 0,883863 & 4,4675 & 0,005450 \\
\hline SI & 0,865419 & 5,2873 & 0,001982 \\
\hline LF & 0,823219 & 7,3013 & 0,000175 \\
\hline SampEn & 0,847833 & 6,1023 & 0,000735 \\
\hline LSY & 0,896183 & 3,9387 & 0,010524 \\
\hline ND & 0,534441 & 29,6179 & 0,000000 \\
\hline F3n & 0,914492 & 3,1791 & 0,027218 \\
\hline Константа & 0,121751 & 245,2579 & 0,000000 \\
\hline
\end{tabular}


Результат відбору «кращої підмножини»

\begin{tabular}{|c|c|c|c|c|c|c|c|c|c|c|c|c|c|}
\hline \multirow[b]{2}{*}{ 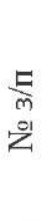 } & \multicolumn{13}{|c|}{$\begin{array}{c}\text { Комбінації змінних } \\
\text { Уілкса (Wilks' } \lambda \text { ) кожного набору (толерантність) }\end{array}$} \\
\hline & $\stackrel{\stackrel{n}{3}}{3}<$ & 胥 & $\begin{array}{l}x \\
\dot{d} \\
\dot{\alpha}\end{array}$ & 酎 & 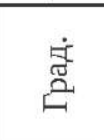 & $\sum_{n=1}^{\infty}$ & 总 & क & 岃 & 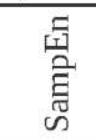 & 药 & 之 & ల్ \\
\hline 1 & 0,0313 & 11 & 553 & 716 & 0,795 & 019 & 233 & 10 & 434 & ,608 & 018 & 672 & ,618 \\
\hline 2 & 0,0338 & 10 & 53 & 0,716 & 0,796 & & 233 & 413 & 0,434 & 608 &, 268 & 0,686 &, 623 \\
\hline 3 & 342 & 10 & 12 & 758 & 0,830 & 0,019 & 235 & 0,425 & 0,434 & 0,608 & 0,018 & 0,682 & \\
\hline 4 & 0,0349 & 10 & 53 & 0,718 & 0,795 & 0,284 & 0,241 & 0,413 & 0,434 & 0,609 & & 0,698 & 0,626 \\
\hline 5 & 0,0354 & 10 & 0,565 & 0,733 & 0,803 & 0,019 & & 0,413 & 0,471 & 0,663 & 0,019 & 0,709 & 0,623 \\
\hline 6 & 0,0361 & 10 & 0,564 & 0,747 & 0,810 & 0,019 & 0,233 & & 0,612 & 0,654 & 0,018 & 0,741 & 0,636 \\
\hline 7 & 0,0366 & 9 & 0,642 & 0,760 & 0,830 & & 0,235 & 0,425 & 0,434 & 0,608 & 0,272 & 0,694 & \\
\hline 8 & 0,0369 & 10 & 0,573 & 0,720 & 0,798 & 0,019 & 0,255 & 0,444 & 0,436 & & 0,018 & 0,746 & 0,618 \\
\hline 9 & 0,0376 & 9 & 0,645 & 0,759 & 0,830 & 0,286 & 0,245 & 0,425 & 0,435 & 0,609 & & 0,704 & \\
\hline 10 & 0,0379 & 10 & 0,559 & 0,834 & & 0,019 & 0,236 & 0,421 & 0,440 & 0,610 & 0,018 & 0,676 & 0,645 \\
\hline 11 & 0,0380 & 10 & 0,577 & 0,737 & 0,806 & 0,019 & 0,253 & 0,582 & & 0,611 & 0,018 & 0,696 & 0,618 \\
\hline
\end{tabular}

Стратегія 2. Покроковий відбір із виключенням. Вихідна модель - всі змінні (33), на кожному кроці перевіряється кожна і виключається та, що не задовольнить критерії відбору (вносить малий вклад у дискримінацію). Умови відбору ті самі. Результат відбору - 13 змінних, 10 - ті самі, що в моделі 1, але замість SampEn з'явились інші ознаки - SODmean, FuzzyEn, SumF. Однак точність класифікації за 13 дискримінантними змінними зменшилася і становила 94,8 \%.

Стратегія 3. Пряме включення, на відміну від покрокового відбору, не передбачає видалення раніше відібраної змінної з моделі. При тих самих умовах відбору отримано той самий набір 11 змінних, як і в моделі 1.

Стратегія 4. Зворотне видалення (backward removal). Оцінюється модель, в яку включено всі можливі пояснюючі змінні. Потім з неї по одній видаляються змінні, що не задовольняють умови на значущість поділу станів. Умови відбору аналогічні попереднім, в результаті в моделі залишилося 12 змінних, 9 я яких ті ж, що і в моделі 1 (САH, Градусник, ND, Average x, SI, SampEn, LSY, PNN50, LF) і три: SODmean, FuzzyEn, SumF. Точність класифікації при застосуванні цієї моделі зменшується до 94,8 \%.

Отже, дві стратегії (покрокове включення і пряме включення) визначили модель 1, що має найбільшу точність класифікації (найменшу експериментальну частку помилок. У табл. 1 подано результати багатовимірного тесту значущості дискримінантної моделі, яка є оптимальною за кількістю змінних (менша) і ефективністю класифікації (найвища).

Стратегія 5. Краща підмножина (best subset) змінних. Для вибору оптимального набору змінних було протестовано модель 1 (11 змінних). На кожному кроці відбувалося видалення однієї змінної з урахуванням внеску дискримінаційної здатності різних комбінацій змінних і толерантності кожної змінної в цьому наборі.

Як відомо, толерантність є мірою мультиколінеарності і визначається як toler $=1-R_{i}^{2}$, де $R_{i}^{2}-$ ко ефіцієнт множинної кореляції $\mathrm{i}$ - ї змінної з усіма іншими. Чим менша толерантність змінної, тим більш надлишкова змінна в моделі, тим меншу додаткову інформацію вона несе.

Результати тестування моделі подано в табл. 2, де на кожному кроці з виключенням однієї зі змінних наведено: Лямбда Уілкса (Wilks’入) комбінації ознак і толерантність змінних. Аналізуючи табл. 2, дійдемо висновку, що отриманий на 2 -му кроці набір з 10 ознак (без RMSSD) є найкращою підмножиною, тому що інші комбінації змінних призводять до зниження дискримінантної здатності (збільшення Wilks’ $\lambda$ )

Дискримінантна здатність набору з 10 ознак (набip ознак № 2) найвища (Wilks’ $\lambda=0,0338, p=0,000$ ), майже така ж, як 11 ознак, а точність класифікації (у \%) не змінилася. Зауважимо, що досягнена точність класифікації за оптимальним набором 10 інформативних ознак дещо менша (95,7 \%), ніж за набором усіх 33 інформативних ознак ВРС $(96,5 \%)$. 

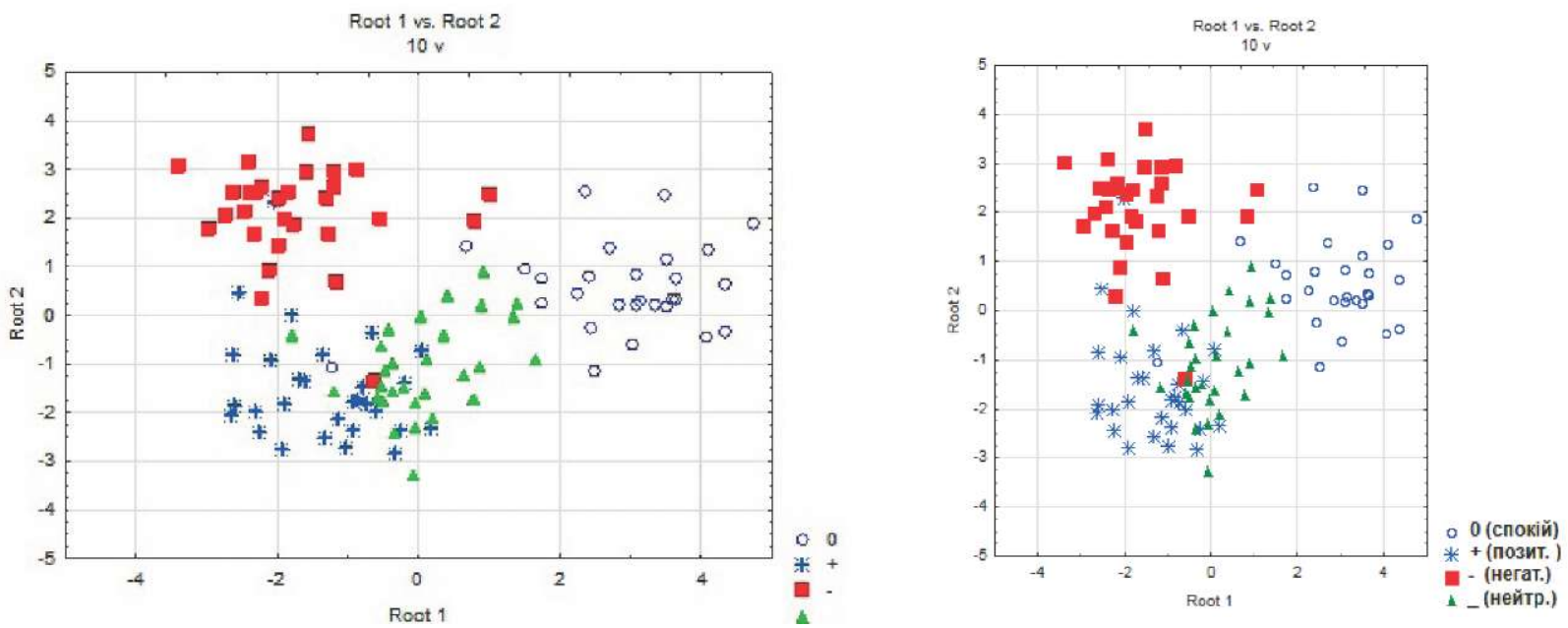

Рис. 1. Діаграма розсіювання канонічних змінних

Методом канонічної кореляції для моделі 310 змінних розраховувалися коефіцієнти дискримінантних функцій, які поділяють стан операторів у спокої та під час перегляду емоційних кліпів.

Результат класифікації чотирьох станів за 10 ознаками наочно представлено на рис. 1, у діаграмі розсіювання значень канонічних змінних кожного оператора. Позначки груп відповідають різним станам операторів (у спокої і при перегляді відеокліпів різного емоційного забарвлення: позитивного, негативного та нейтрального).

Відмінності середніх значень трьох дискримінантних функцій високозначущі. Практично всі відмінності $(82,9$ \% мінливості канонічних змінних) визначаються двома першими дискримінантними функціями. У першої дискримінантної функції (D1) найнижче значення Лямбда Уілкса (Wilks'A=0,0312), що означає найбільшу здатність розділяти стани. Це дає можливість використовувати першу дискримінантну функцію для створення моделі індексу емоційної реакції:

$$
\begin{aligned}
& \text { D1=0,528CAH-0,068Градусник- } \\
& -1,756 \text { AverageX+0,434PNN50+0,605SI+ } \\
& +0,125 L F+0,411 \text { SampEn-0,38LSY- } \\
& -0,78 N D-0,046 F 3 n
\end{aligned}
$$

Результати класифікації, що дають уявлення про ефективність розпізнавання за відібраними ознаками (показниками самооцінки і вісьмома ознаками ВРС), подано в табл. 4. Частка загальної кількості правильно класифікованих спостережень (коефіцієнт результативності) становить 95,7 \%.

Для трьох етапів дослідження (стан спокою, перегляд позитивного, негативного відеокліпів) отримано високий відсоток $(96,5$ \%) збігів з апріорною класифікацією.

Помилкове визначення стану сталося у п'яти випадках:

1) стан спокою для оператора nom $=16$ класифiковано як реакцію на позитивний відеокліп;

2) реакцію на позитивний відеокліп класифіковано як на негативний стимул для оператора nom $=24$;

3) реакцію на негативний відеокліп класифіковано як реакцію на позитивний стимул для оператора nom $=21$; (зауважимо, що саме ця помилка відсутня за умов розпізнавання за повним набором інформативних ознак);

4) реакцію на перегляд нейтрального відеокліпу у двох випадках класифіковано неправильно для оператора nom $=4$ - як стан спокою, а для nom $=5$ - як реакція на позитивний стимул.

Матриця класифікації за показниками самооцінки та інформативним ознаками ВРС

Таблиияя 4

\begin{tabular}{|c|c|c|c|c|c|}
\hline \multirow{2}{*}{ Етапи } & \multirow{2}{*}{ Точність класифікації, \% } & \multicolumn{3}{|c|}{ Стан операторів на етапах дослідження (кількість спостережень) } \\
\cline { 3 - 6 } & & 0 & + & - & - \\
\hline 0 & 96,55 & 28 & $1($ nom=16) & 0 & 0 \\
\hline+ & 96,55 & 0 & 28 & $1($ nom=24) & 0 \\
\hline- & 96,55 & 0 & $1($ nom=21) & 28 & 0 \\
\hline- & 93,10 & $1($ nom=4) & $1($ nom=5) & 0 & 27 \\
\hline Всього & 95,68 & 29 & 31 & 29 & 27 \\
\hline
\end{tabular}


Матриця класифікації за показниками ВРС

\begin{tabular}{|c|c|c|c|c|c|}
\hline \multirow{2}{*}{$\begin{array}{c}\text { Етапи } \\
\text { дослідження }\end{array}$} & \multirow{2}{*}{$\begin{array}{c}\text { Точність } \\
\text { класифікації, \% }\end{array}$} & 0 & + & \multicolumn{4}{|c|}{ Кількість випадків } \\
\cline { 3 - 6 } & 93,10 & 27 & 0 & 1 & 1 \\
\hline 0 & 82,75 & 0 & 24 & 5 & 0 \\
\hline+ & 62,07 & 0 & 7 & 18 & 24 \\
\hline- & 82,75 & 0 & 0 & 5 & 29 \\
\hline Всього & 80,17 & 27 & 31 & 29 & 24 \\
\hline
\end{tabular}

Можна зробити висновок про можливість ефективного розпізнавання емоційних реакцій за показниками самооцінки та інформативним ознаками ВРС за дискримінантної моделлю (1).

Якщо виключити 3 дискримінантної моделі показники самооцінки емоційного стану (CAH, Градусник), то коефіцієнт результативності класифікації знижується до 80,17\%. Результати класифікації тільки за інформативними ознаками ВРС (Average X, PNN50, SI, LF, SampEn, LSY, ND, F3n) подано в табл. 5.

Як бачимо (табл. 5), більшість помилок стосується класифікації реакції на негативний стимул.

Розпізнання емоційних реакцій тільки за показниками самооцінки (без показників ВРС) виявилося найменш ефективним. Хороший результат отримано тільки для розпізнавання реакції на сильно емоційно забарвлені стимули різних знаків $(82,7$ та $86,2 \%$, для позитивного і негативного відповідно), а в спокої і при перегляді нейтрального відеокліпу точність класифікації незадовільна (відповідно 27,5 і $59,5 \%$ ).

Результати класифікації тільки за інформативними ознаками ВРС (без урахування показників са- мооцінки) при різних парних варіантах порівнянь: вихідного стану та перегляду тестових відеокліпів, а також при попарному порівнянні різних етапів дослідження подано в табл. 6.

Необхідно зазначити, що за допомогою 8 показників ВРС найефективніше розпізнаються стан спокою та реакція на позитивний стимул (без помилок). Для розпізнання реакції на стимули різної модальності (позитивний, негативний, нейтральний) виявилися значущими вклади різних комбінацій з набору інформативних ознак поданих в порядку зменшення їх вкладу (табл. 6).

Отже, запропонований двоетапний метод відбору інформативних ознак показав можливість ефективного розпізнавання реакції операторів на емоційно забарвлені тестові стимули за комплексом восьми характеристик ВРС. До переліку ознак -маркерів емоційної реакцій увійшли стандартні показники ВРС: Average $x$ - середне значення RR -інтервалів; PNN50 - частка (\%) від загальної кількості послідовних пар $R R$ - інтервалів, які розрізняються більше ніж на 50 мс; $S I$-індекс напруження регуляторних систем

Таблиия 6

Точність класифікації за парними порівняннями станів операторів згідно з показниками ВРС

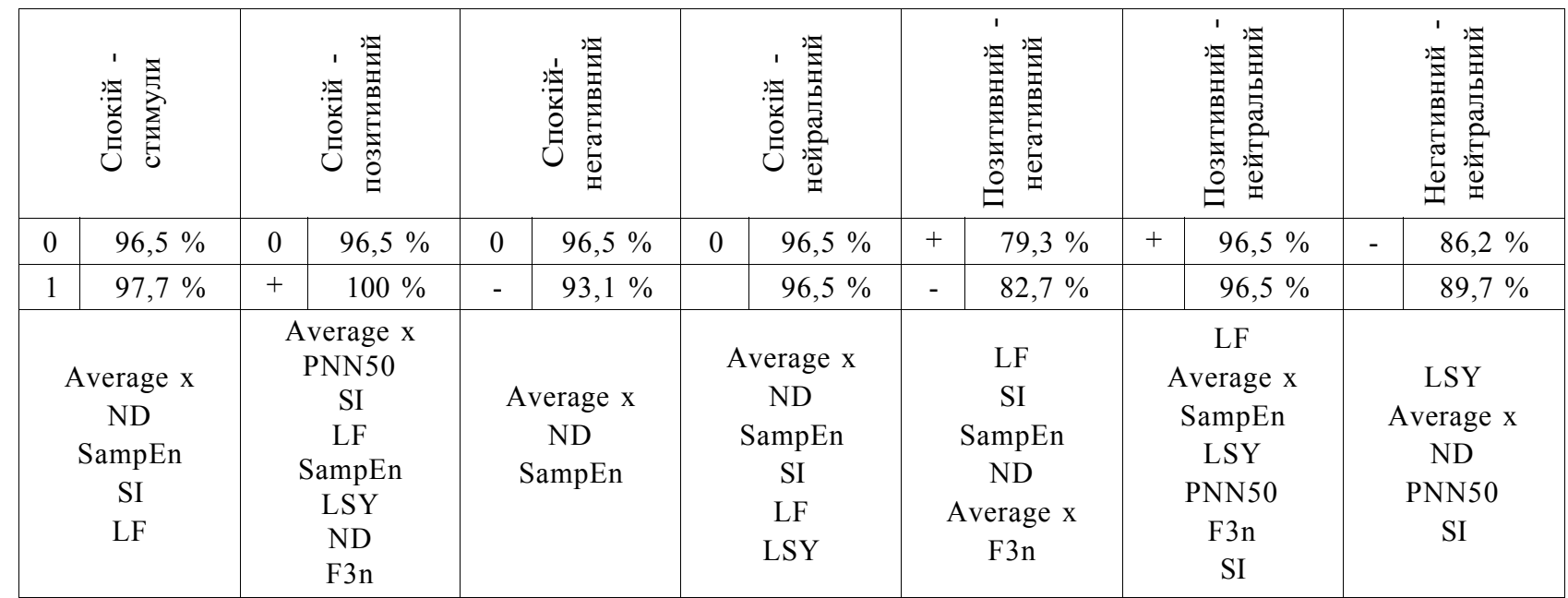


(стрес -індекс); $L F$ - потужність спектра в діапазоні (0,15 -0,04 Гц) [13, 14]. Окрім того, ще три ознаки є характеристиками графу ритму серця: $N D$ - кількість вузлів графу; $L S Y$ - середня сума квадратів відхилень вузлів графа від лінії регресії вздовж осі $Y$; $F 3 n$ - сумарний процент накопиченої частоти за першими трьома рангами циклічних компонент від загальної суми частот [15], а також показник SampEn (ентропія шаблонів), що $\epsilon$ мірою нерегулярності і складності нелінійної динаміки ритму серця [16-17].

Висновки. Вдосконалено методику відбору інформативних показників ВРС для розпізнавання реакції операторів на емоційні стимули різної модальності. Методика включає застосування дисперсійного, покрокового дискримінантного аналізу 3 різними стратегіями відбору ознак до стандартизованих відхилень відносно індивідуальних середніх значень показників ВРС.
Методика дала можливість виділити набір інформативних показників ВРС, зміни яких $є$ маркером реакцій оператора на тестові стимули різної модальності Лінійну комбінацію показників (самооцінки та інформативних ознак ВРС) може бути використано як індекс для визначення реакції оператора на тестові стимули різної модальності. Коефіцієнт результативності розпізнавання емоційних реакцій на стимули різної модальності за цим індексом - 95,7 \%.

Найвищу точність класифікації тільки за інформативними ознаками ВРС отримано для розпізнання стану спокою та реакції на позитивний емоційно забарвлений відеокліп (96,5 та $100 \%$ відповідно). Найбільш інформативні ознаки такі: середнє значення $R R$-інтервалів, стрес -індекс, часовий індекс $P N N 50$, спектральний показник $L F$, деякі показники графу серцевого ритму та показник нелінійної динаміки ритму серця.

\section{Література.}

1. Lang P. Looking at Pictures Affective, Facial, Visceral, and Behavioral Reactions / Lang P., Greenwald M., Bradely M., Hamm A. // Psychophysiology. - 1993. - Vol. 30. - № 3. - P. 261 -273.

2. McCraty R. The effects of emotions on short term heart rate variability using power spectrum analysis / McCraty R., Atkinson M., Tiller W. et al. // American Journal of Cardiology. - 1995. - Vol.76. - № 14. - P. 1089 -1093.

3. Picard R.W. Toward Machine Emotional Intelligence Analysis of Affective Physiological State / Picard R.W., Vyzas E., Healey J. // IEEE Transactions on Pattern Analysis and Machine Intelligence. - 2001. - Vol. 23 (10). - P. 1175 - 1191. 4. Nasoz F. Emotion Recognition from Physiological Signals for Presence Technologies / Nasoz F., Alvarez K., Lisetti C., Finkelstein N. // International Journal of Cognition, Technology and Work, Special Issue on Presence. - 2004. Vol. 6. - № 1. - P. 1 - 14 .

5. Lisetti C. L. Using noninvasive wearable computers to recognize human emotions from physiological signals / Lisetti C. L., Nasoz F. // Journal on Applied Signal Processing 2004 (11). - P. 1672-1687.

6. Kreibig, S. D. Cardiovascular, electrodermal, and respiratory response patterns to fear - and sadness -inducing films / Kreibig, S. D., Wilhelm F. H., Roth W. T., Gross J. J. // Psychophysiology. - 2007. - Vol. 44. - P. 787-806.

7. Wagner J. From Physiological Signals to Emotions: Implementing and Comparing Selected Methods for Feature Extraction and Classification / Wagner J., Kim J., Andre E. // ICME. - 2005. - P. 940-943.

8. Appelhans B. M. Heart rate variability an index of regulated emotional responding / Appelhans B. M., Luecken L. J. // Rev. Gen. Psychol. - 2006. - № 10. - P. 229-240.

9. Van den Broek E.L. et al. Affective man -machi-ne interface: unveiling human emotions through biosignals// Biomedical Engineering Systems and Technologies. - Springer Berlin Heidelberg. - 2010. - P. 21-47.

10. Jerritta S. et al. Physiological signals based human emotion recognition: a review // Signal Processing and its Applications (CSPA), 2011 IEEE 7th International Colloquium on IEEE. - 2011. - P. 410-415.

11. Можливості аналізу варіабельності ритму серця в діагностиці емоційного стану людини / Чайковський І. А., Кальниш В. В., Єна Т. А. и др. // Медична інформатика та інженерія. - 2011. - № 1. - С. 57-62.

12. Кальныш В. В. Многомерный статистический анализ объективной и субъективной составляющей реакции на эмоциональное воздействие: методические аспекты / Кальныш В. В., Чайковский И. А., Кривова О. А. и др.// Клиническая информатика и телемедицина. - 2013. -№10, - С. 175 -76.

13. Баевский Р. М. Анализ вариабельности сердечного ритма при использовании различных электрокардиографических систем (методические рекомендации) / Баевский Р. М., Иванов Г. Г., Чирейкин Л. В. // Вестник аритмологии. - 2001. - № 24. - С. 65-87.

14. Heart rate variability. Standatds of Measurement, Physiological interpretation and clinical use // Circulation. - 1996. V.93, - P. $1043-1065$.

15. Машин В. А. Анализ вариабельности сердечного ритма с помощью метода графа. Физиология человека. 28 (4) : $63-73.2002$. 
16. Richman J. S. / Richman J. S., Moorman J. R. // Am. J. Physiol. - Heart Circ. Physiol. - 278, H2039 (2000).

17. Pincus S. M. Physiological time-series analysis: What does Regularity Quantify / Pincus S. M., Goldberger A. L.// American Journal of Physiology. - 1994. - (Heart Circ Physiol), 35.1643-656.

18. Дженнрич Р. И. Пошаговый дискриминантный анализ. Статистические методы для ЭВМ. - М. : Наука, 1986. C. 94-112. 